\title{
The Impact of Social Media on the Promotion of Commodities for Small Projects in the State of Kuwait
}

\author{
Khaled, Al-Duraiban \\ The World Islamic Sciences and Education University / PhD in Business Administration in jordan
}

\begin{abstract}
The current study aimed at identifying the impact of social media on promotion of commodities for small projects in the State of Kuwait. The study population consisted of all workers in small projects, and they numbered (720) workers. A simple random sample of (250) workers was chosen. The study concluded that there is a statistically significant effect of the elements of social media (conversations, groups, participation, partnership, relations) in promoting the commodities of small projects in the State of Kuwait; the study also reached a number of recommendations, the most important of which are:

The need for those in charge to focus on social media, (Facebook, Instagram, Twitter and LinkedIn) as a means of communication with customers in order to promote of commodities for small projects in the State of Kuwait because of its characteristics and advantages, focusing on giving social media more care and attention to the mechanism of adopting credible and reliable information to reach those wishing to establish small projects in the State of Kuwait, as this information helps them in adopting their projects, the need for those in charge of social media to encourage the owners of implemented projects to share their own experiences and expertise to enhance new projects owners.
\end{abstract}

Keywords: Social Media, Promotion of Commodities for Small Projects, Kuwait.

DOI: $10.7176 / \mathrm{NMMC} / 89-03$

Publication date: April $30^{\text {th }} 2020$

\section{Introduction}

Social media has shown, over a decade, an increasing association in the daily life of individuals and commercial operations, and in interaction on promotion of commodities for small projects in the State of Kuwait, and we will not be far from the truth if we say that social media has become a basic necessity in our everyday personal life, on promotion of commodities for small projects in the State of Kuwait.

Social media does not rely solely on simply sending information to the promoters of small projects goods in the State of Kuwait, and in order to motivate them, and encourage them in newspapers, TV and films. Social media provides unprecedented opportunities for small projects to deliver their marketing messages to their target customers directly, and plays an important role in influencing their purchasing behaviors, and small projects have begun to adopt them as a marketing tool for them of strength, capabilities, and impacts that make them benefit from them, and work to develop a way that he performed her work in accordance with that.

The promotion of small projects is not immune to the services provided by social media, but rather it has a large share of interactivity in those means, and attracting its fans and customers, as customers publish information, pictures and videos directly through their electronic devices and clarify their experiences and their awareness of meals, types and quality of services provided in the restaurant. This leads to the formation of a mental image closer to reality, as this interaction is due to personal experiences and propaganda.

This study focuses on the subject of social media, in order to identify it through its main dimensions (conversations, groups, participation, partnership, relations) and determine its impact on achieving the promotion of commodities for small projects in the State of Kuwait.

\section{Problem of the Study}

The problem of the study in the urgent need for small projects in the State of Kuwait to reveal preferences for the promotion of commodities, and their basic dimensions, and how to form these preferences, and to identify the factors affecting them, this is in order to develop the marketing process in line with these preferences, which is reflected in achieving the desired goals from social media, as it is one of the modern marketing tools that guarantees communication, direct and continuous interaction with customers, and represents an important source of information.

\section{Study Questions}

The study is represented by the following main question:

"What is the impact of social media Facebook, Instagram (conversations, groups, participation, partnership, relations) in achieving the promotion of commodities for small projects in the State of Kuwait?"

The following sub-questions branch out of this main question:

What is the extent of social media conversations in on promotion of commodities for small projects in the State of 
Kuwait?

What is the extent of the practice of social media participation in on promotion of commodities for small projects in the State of Kuwait?

What is the extent of social media groups' practice in on promotion of commodities for small projects in the State of Kuwait?

What is the extent of social relations relationships on promotion of commodities for small projects in the State of Kuwait?

\section{Importance of the study:}

The importance of this study comes from:

1. Trying to focus on the importance of social media and its impact on promotion of commodities for small projects in the State of Kuwait to workers and keeping abreast of everything new in the topic of promoting in social media. 2 . The researcher hopes that this study represents a motivation for many researchers to study social media topics and on promotion of commodities for small projects in the State of Kuwait in various economic institutions and sectors.

\section{Objectives of the Study}

This study aims to: Identify the impact of social media (conversations, groups, participation, partnership, relations) in achieving the on promotion of commodities for small projects in the State of Kuwait.

1. Contribute to developing a theoretical and conceptual framework for the study

2. Make useful recommendations in the field of social media and promotion of commodities for small projects in the State of Kuwait

\section{Hypothesis of the Study}

To achieve the objectives of the research by studying the impact of the dimensions of social media on promotion of commodities for small projects in the State of Kuwait, it has been relied on a set of hypotheses, as follows:

Ho1: "There is no statistically significant effect at the level of significance $(\boldsymbol{\alpha} \leq 0.05)$ the dimensions of social media (conversations, groups, participation, partnership, relations) in promotion of commodities for small projects in the State of Kuwait

Ho1 - 1: "There is no statistically significant effect at the level of significance $(\alpha \leq 0.05)$ of the talks in promotion of commodities for small projects in the State of Kuwait

H01 - 2: "There is no statistically significant effect at the level of significance $(\boldsymbol{\alpha} \leq 0.05)$ to participate in promotion of commodities for small projects in the State of Kuwait

H01 - 3: "There is no statistically significant effect at the level of significance $(\alpha \leq 0.05)$ for the groups on promotion of commodities for small projects in the State of Kuwait

H01-4: "There is no statistically significant effect at the level of significance $(\alpha \leq 0.05)$ of the relationships in on promotion of commodities for small projects in the State of Kuwait.

\section{Study Model:}

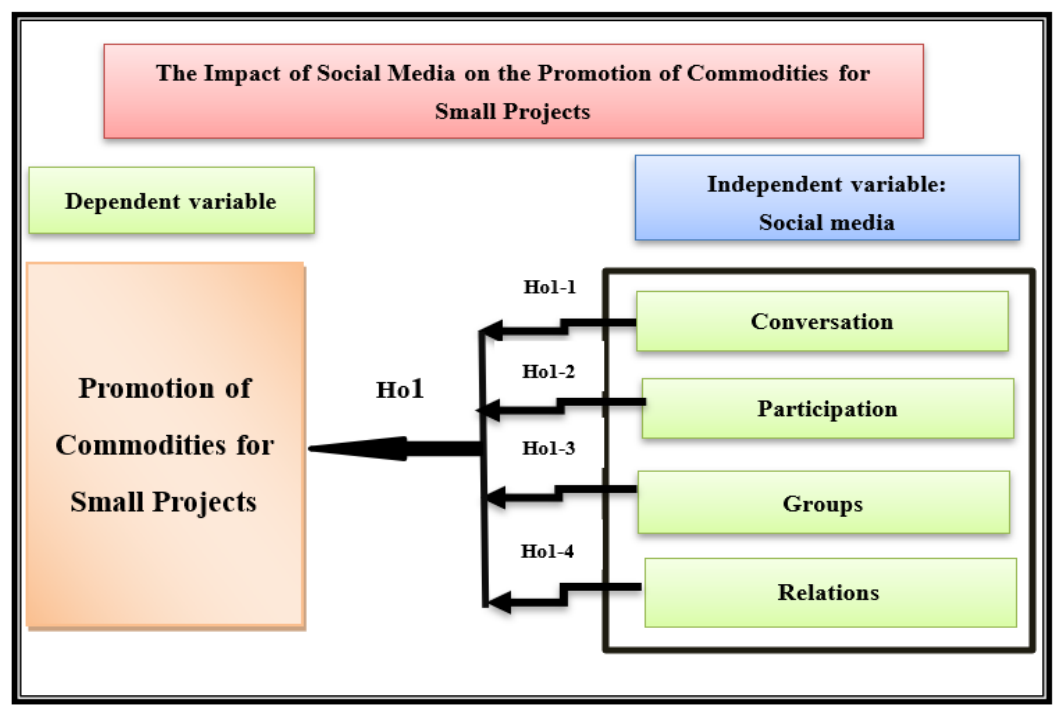

* The study model was prepared by the researcher, acting accordingly and based on the following previous studies: As it was based on its components on: (Andzulis, Rapp \& Agnihotri, 2014) (Hussein, 2006) 


\section{Literature Review}

Previous studies:

Quboo' (2016) study: The Impact of Using Social Media Networks on Knowing Customers, Acquiring and Maintaining Customers: Case Study in (Marka VIP) Company.

This study aimed to demonstrate the impact of using social media networks on the knowing customers and acquiring them through a case study in (Marka Vip) company, where the study worked on a comprehensive survey of all employees of (Marka Vip) and the researcher worked on designing a questionnaire to collect information and to achieve the purpose of the study, (100) questionnaires were distributed to the members of the study population, and (98\%) of the questionnaires were retrieved. the data was analyzed and the hypotheses were chosen by using SPSS 16 program, the study concluded several results, the most important of which are: the presence of an impact on the use of social networks (Facebook, Twitter, YouTube) on the knowledge of customers, The company's use of social media networks (Facebook, Twitter, YouTube) helped the company to retain existing customers from the point of view of the study sample individuals as the company builds a strong relationship based on trust between it and its customers and it also helped social networks target new customers for the company from different categories.

What distinguishes the researcher of this researcher study is that this study revealed the impact of the elements of social networks (Facebook, Twitter, YouTube) on the knowledge of customers and their retention and acquisition while the current study showed the impact of social media (Facebook, Twitter and mobile applications) on the application of the marketing strategy in non-profit organizations.

The study recommended the necessity of using Facebook and blogs, activating them in marketing campaigns, publishing links to these methods on various web pages, and the need to focus on the degree of safety of information on the Facebook page because it constitutes a sensitive point, and is important to users, the importance of finding and following groups and belonging to them, and disseminating information Through these groups because of its great influence on its members.

(Liu \& Lopez, 2016) Study: "The impact of social media conversations on consumer brand choices.

This study aimed to assess the impact of conversations via social media, on consumers 'evaluation of the characteristics of the brand, and the demand for soft drinks, and to achieve the goals of the study, a separate selection model for consumer demand was developed, to test conversations on social media Facebook, Twitter and YouTube, depending on Nesslon soft drink company information.

The study found that customer conversations about brands, and the nutritional aspects of soft drinks, have a significant and important impact on their assessments of the characteristics of the brand, and in their choices of soft drinks, and the study also showed that conversations on social networking sites give indications of customers 'preferences for certain characteristics in products and services.

The study recommended that companies use social media as a strategic tool to efficiently promote the brand, and the need for governments to carry out promotional campaigns to increase the intensity of conversations about sugar, high calories, and their negative impact on customers, and the need to always pay attention to the trends and preferences of the customers that they highlight about the characteristics and control of products.

(Song \& Yoo, 2016) Study:

" The role of social media during the pre-purchasing stage" .

This study aimed to test whether social media affects the purchasing decision of customers during the pre-purchase phase of service consumption, and to achieve the goals of the study, 285 electronic questionnaires were distributed to active consumers on social media.

The study found that there is a positive relationship between the benefits of social networking sites and the purchasing decision of customers, and this is clearly demonstrated in the functional benefits such as the degree of relevance and effectiveness and information, and the dissemination of experiences, and in the financial benefits achieved.

The study also showed that there is no significant impact of the social and psychological benefits of social media on the purchasing decision of customers.

The study recommended the necessity of taking a larger random sample in future studies, in order to generalize its results more, in addition to the need to use new variables, and conduct the study on new market parts, and the study emphasized the need to address concepts of the relationship between social media, customer satisfaction and loyalty, and the necessity of conducting studies about restaurants, as an important market part, and trying how social media can affect their performance.

(Edan, 2015) Study: Using social media to perform customer relationship management.

This study aimed to demonstrate the impact of social networks on the performance of customer relationship management as a field study in private Jordanian universities, where this study examined both the impact of customer orientation and targeted information technology in managing customer relationships in addition to the customer-based administrative system in achieving the performance of customer relationships,

The study relied on the descriptive analytical approach. The study tool was represented in a special 
questionnaire for all the information distributed to the study sample community. The study community consisted of some Jordanian private universities, which are the Middle East University, Al-Ahliyya Amman University and Isra'a University, while the study sample was represented by students who numbered (375) male and female students.

The study concluded many results, the most prominent of which was a positive impact of customer orientation and targeted technology in the customer relationship management process, which is represented in (customer satisfaction and customer loyalty). The study also showed that there is a positive impact of the capabilities of customer relationship management, which is represented in (customer interaction management, response and information dissemination) as an intermediate variable.

What distinguishes the researcher's study from this study is that it studies the impact of social media on the marketing strategy in non-profit organizations in Jordan and that the previous study focused on the impact of social networks in managing customer relationships.

\section{Social media:}

Recent years have witnessed tremendous developments that have become huge challenges to marketing with the beginning of a new millennium, perhaps the most prominent of which are technological developments, whether at the level of markets, or the arts of production, or means of communication with customers.

The emergence of the Internet is considered one of the most important technological revolutions in the modern era, as it by nature does not require a high cost, and it allows its users - from all parts of the world - to access it easily, which made it a good platform for companies to communicate with their customers efficiently.

With the advent of the direct communication revolution and the interaction of the facility with its client personally, the facility and the customer have become face to face, dealing together through organized interaction through modern interaction tools that greatly exceed the capabilities of the personal seller in time and movement, and means of explanation and clarification.

The concept of social media: The definitions of social media have varied according to the many concepts associated with them, and the following is a presentation of a number of the most prominent of these definitions: Define them (Kaplan \& Haenlein, 2010, 60): As a service provided on the Internet, it allows individuals to practice several things such as building relationships with other members, using these means to entertain through the games available to them, and social communication with others, and also allows the creation and exchange of user-created content, and the exchange of information, about similar interests, and discuss their favorite topics.

It defines it (48, Miller, 2015) as the sites, services, and online platforms that individuals use to share their experiences, opinions, interests, and information they have with other individuals.

Looking at these and other definitions, we can define the following main elements on which the integrated definition of social media is based (Beshmaf, 2016) (Obaidat and Al-Ghadeer, 2011):

- $\quad$ It has various and different means in its designs.

- $\quad$ It introduces itself to all the people who are interested as networking sites.

- $\quad$ It provides its services via electronic communications.

- Methods of communication through it include text messages, instant and indirect chats, video calling, and comments.

- It allows the exchange of information, opinions, and ideas among interested individuals.

Accordingly, it can be defined as "various and diverse electronic platforms, in its systems, forms, and services, on the Internet that provide its users with an opportunity to dialogue and exchange information, opinions and ideas through personal files, photo albums, video sharing, and chat rooms."

The most popular social media:

(Facebook): It is considered one of the most popular social media, and among the sites that help individuals to highlight themselves and their personalities, interact with others, and exchange content of all kinds. This site was established by Mark Zuckerberg in (2004) for the purpose of communication between students in Harvard university, and then its use spread among other university students in America, Britain and Canada, and the site subsequently evolved from just a place to display personal photos to a communication channel between electronic societies.

Facebook provides many advantages for social media pioneers, as it allows members to send and receive messages, conduct instant conversations, follow other people's posts, create pages, and create groups. Facebook is also one of the most used social media because of its ease of use and its many advantages. (Hamdan, 2016). (Dunbar, Arnaboldi \& Passarella, 2015, 42).

(Twitter): It is a social media site that provides a microblogging service, which allows its users to send updates (Tweets) about their condition with a maximum of (140) characters per message, directly via Twitter, or send an SMS, or instant chat programs.

There are many uses of Twitter not only on the personal side, but also on the commercial side, as it provided the possibility to announce some of the works and special achievements, and there has become a demand for it as a promotional and advertising means by many business organizations. (29, Ezumah, 2013). 
(Linked In): This network was created in (2003), and this network is considered one of the social and professional means, as this network focuses on the skills and competencies that individuals possess, in addition to their job accomplishments and their experiences, unlike many of the means that focus on Personal details for users, and this network allows individuals looking for work, distinguished individuals, and qualified to obtain jobs through their association with organizations and businessmen, building relationships with them, and highlighting their technical and administrative skills and capabilities. This is done by displaying a CV that usually includes the level of education and previous experience of individuals, on the site and sharing it with others to see it (Thelwall, 2009, 27).

(Instagram): It is a social network for the exchange of photos and videos, launched in October (2010), allowing users to take pictures and videos, and this network allows to filter these pictures and videos, make adjustments to them, and share them with friends and followers, and at the beginning Instagram support was on IPhone, iPad, and iPod Touch

In April (2012), the Instagram network added support to the Android platform, as the network became available on the screens of smart phone devices such as Samsung devices, which led to increased use and spread among the audience of users. (54, Miller, 2015).

(Snapchat): It is a social networking application for recording, broadcasting and sharing picture messages developed by Evan Spiegel and Bobby Murphy, then Stanford University students. Through the application, users can take pictures, record videos, add text and graphics, and send them to the recipient's control list. These photos and videos are known to be "snapshots". Users set a time limit for displaying their snapshots from one to ten seconds, after which messages will be deleted from the recipient's device and deleted from Snapchat's servers, also, but some applications that save the displayed video have been programmed by a simple principle which is to penetrate Snapchat in a simple way form of several companies. The application was subjected to acquisition attempts characterized by a yellow color in all its advertisements and advertisements. (Miller, 2015, 54).

The basic components of social media: There are several main components of social media, called units or functional blocks of social media, as these studies have underscored the importance of the following elements as basic components of social media, which are as follows (Al-Dibsi and Chefs, 2013):

(Conversation): It represents the extent to which users interact and communicate with each other in the form of text messages about specific issues, where one of the users begins the conversation by adding specific content that pushes other users to respond to it, and the conversations are done through social media in an open and direct manner, allowing for users to discuss, dialogue and express an opinion, as this conversation can take place between two users, and take various forms, such as text messages, oral conversations, and video chats, and there can be millions of users who watch and interact with these conversations. (Henderson \& Bowley, 2010, 240).

(Sharing): Sharing is an important aspect of social media. Through participation, users can receive, send, distribute, and exchange content between them. The content that is shared is the main element that mediates the relationship between users. It is the reason for their interconnectedness and encounters on the Internet, and sharing information with others is a social behavior with two types of determinants. What information should be shared? With whom is this information shared? (Sohn, 2009, 225).

Users share the content represented by their information, images, or video files, while users who receive this content may be interested in its content, and they may also re-share it again with other users. (Lee \& Ma, 2012, 332).

(Osatuyi, 2013,228 ) indicates that users tend to share content (information, photos, videos) and republish it whenever this content is credible, reliable, reliable and can benefit from it. Examples of participation include Twitter tweets, conversations, customer reviews and ratings, on Facebook pages.

Thus, we find that the perceived quality and user preferences of the content (information, images, and videos) determine the extent to which users want to share this content with other users via social media.

(Groups): Groups in social media refer to Communities that users can join, or create, in the virtual world, through social media platforms, and these groups may be either major groups, characterized by inclusiveness and dealing with a general topic, Or Subgroups, are concerned with topics that fall under and subdivide the main group. (Fulcher, 2014, 10).

Users create groups for the purpose of communicating, and interacting with other users, where content (information, photos, and videos) are exchanged about interests, issues, and common opinions, or join groups that include individuals with similar interests and opinions and issues of common interest with them. (165, Tang \& Liu, 2010).

(Relationship): It expresses the ability for users to connect with other users, and make friends with each other within the social media environment, where users have the freedom to communicate with other users and offer to link with them, and make friends with them, especially if there are personal relationships or shared interests. Among users, some social media also make suggestions to link with other users based on their previous choices. Relationships in social media refer to the way in which users relate to each other in the virtual community with the goal of social media and content exchange, and therefore the relationships offered by social media platforms 
determine what, and how, the content exchange between users, and these relationships may be official and organized, as in Facebook network, or unofficial and unorganized, as is the case in Twitter network (Trainor etal., 2014, 103)

Promoting commodities for small projects: The principles of promotion, even if they are the same in each of the service and industrial production sectors, except that the practice in the service field may not be identical with that pursued by the industrial establishment.

The promotion of services faces some difficulties compared to material goods, and the reason is due to the characteristics of services, especially the intangible property. Promotion is defined as "coordination between the seller's efforts to establish information outlets and to facilitate a good or service or to accept a specific idea."It is also known as "that part of the communication that aims to inform and remind the consumer of the good or service produced by the company and influences it for its acceptance and use." (George et Berry).

Emphasis must be placed on the promotion being effective according to the spoken word and pledging what is possible, for the promise must match the accuracy of the offer. Giving concrete symbols, i.e. embodying the service, either with logos or in a tangible way Continuity to convince prospective clients of the validity of the offer (El Sayed, Abdel Aal, 2009).

The relationship of communication with promotion: Promotion is one of the types of communication, and it is called marketing communications, and many traditional poor people have failed to realize that the various promotional marketing tools must be coordinated between them to create effective communications, and from this the idea of integrated marketing communications arose, especially in American companies During the eighties of the last century, integrated marketing communications mean the establishment of integration between the various elements of promotion on the one hand, and between the various other marketing activities on the other hand that relate to the clients of the institution.

A working group from the American Association of Media Agencies has developed or defined the definition of integrated marketing communications, which is "It is a concept for marketing communication planning that focuses on the added value of a comprehensive plan that takes into account the value of the strategic role of various communication fields such as advertising and direct marketing, sales promotion, public relations, mixing and linking between These areas are to have a clear, consistent, and highest impact for communications "(Al-Nsour, Al-Manasrah, and Ziadat, 2016). Social media dimensions in promoting small projects goods

9. Study methodology: The researcher relied on the sampling strategy, which is based on the inferential method to answer the study's questions and its various hypotheses, using inferential statistics to reach the relationship and impact.

10. Study population: study population consists of all workers in small projects in the State of Kuwait and their number is (720) workers. The simple random sample of (250) workers was approved. The analysis unit consists of workers (director, deputy director, marketers, administrative).

Study tool stability test: The internal consistency factor Cronbach's Alpha was calculated, as the results were, as follows, for all study variables: Table (1) values of the internal consistency factor for the dimensions of the study tool.

\begin{tabular}{|c|c|c|}
\hline No. & Dimension & Alpha value \\
\hline 1 & CONVERSATIONS & 0.82 \\
\hline 2 & PARTICIPATE & (2.88 \\
\hline 3 & GROUPS & 0.79 \\
\hline 4 & RELATIONS & $\mathbf{0 . 8 1}$ \\
\hline 5 & Promotion of commodities for small projects & $\mathbf{0 . 8 5}$ \\
\hline
\end{tabular}

We note in Table (1) that the values of the internal consistency factor of the Cronbach alpha for the dimensions of the study tool ranged (0.88- 0.77), therefore all values are greater than $(0.60)$ and this is an indication of the consistency between the dimensions of the study tool, the reliability of the study tool and the ability to rely on it for statistical analysis.

Consequently, the consistency coefficients of the study instrument and its fields are valid and sufficient indicators for the purposes of statistical analysis.

Study hypotheses testing: The main hypothesis was subjected to multiple linear regression analysis, while the branched hypotheses were chosen for simple linear regression analysis for the results were as follows:

Ho1: "There is no statistically significant effect at the level of significance $(\alpha \leq 0.05)$ dimensions of social media (talks, participation, groups, relationships) in promoting the commodities of small projects in the State of Kuwait." 


\begin{tabular}{|c|c|c|c|c|c|c|c|c|c|c|}
\hline \multirow{2}{*}{ Ind } & \multicolumn{2}{|c|}{$\begin{array}{c}\text { Model } \\
\text { Summery } \\
\end{array}$} & \multicolumn{3}{|c|}{ ANOVA } & \multicolumn{5}{|c|}{ Coeffecient } \\
\hline & $\mathbf{R}$ & $\mathbf{r}^{2}$ & $\mathbf{F}$ & Df & Sig F & Dep & B & S.R & $\mathbf{T}$ & $\operatorname{Sig} t^{*}$ \\
\hline \multirow{4}{*}{$\begin{array}{l}\text { promoting } \\
\text { commodities } \\
\text { of small } \\
\text { projects }\end{array}$} & \multirow{4}{*}{.6850} & \multirow{4}{*}{0.469} & \multirow{4}{*}{10.425} & \multirow{4}{*}{5} & \multirow{4}{*}{0.000} & CONVERSATIONS & $\begin{array}{l}0.088 \\
\end{array}$ & 0.049 & 2.110 & 0.011 \\
\hline & & & & & & \begin{tabular}{|l|} 
PARTICIPATE \\
\end{tabular} & 0.029 & 0.050 & 5.522 & 0.000 \\
\hline & & & & & & GROUPS & 0.152 & 0.059 & 3.250 & 0.001 \\
\hline & & & & & & RELATIONS & 0.068 & 0.068 & 1.734 & 0.075 \\
\hline
\end{tabular}

The results of Table (2) indicate that the correlation coefficient $(\mathrm{R}=0.685)$ indicates the relationship between the independent variables and the dependent variable, and the effect of the independent variables (social media dimensions) on the dependent variable (merchandise promotion for small projects) is a statistically significant effect, where The calculated value of $\mathrm{F}$ is $(10.425)$, with a significance level $(\mathrm{Sig}=0.000)$ which is less than 0.05 , where it appeared that the value of the determination coefficient $(\mathrm{R} 2=0.469)$, which indicates that $(47 \%)$ of the variance in (promoting small business commodities) can be explained by the variance in (the dimensions of social media) combined.

As for the table of coefficients, it has been shown that the value of B at the distance of (the talks) has reached $(0.088)$ and that the value of $\mathrm{t}$ at it is $(2.110)$, and at the level of significance $(\mathrm{Sig}=0.011)$, which indicates that the effect of this dimension is significant. The value of B at the (groups) dimension was (0.152), and the value of $\mathrm{t}$ at $(3.250)$, with a significance level ( $\mathrm{Sig}=0.001)$, indicating that the effect of this dimension was significant. The value of $\mathrm{B}$ at the (relationships) dimension (0.068) and the value of $\mathrm{t}$ at (1.734), with a significance level (Sig $=0.075)$, indicating that the effect of this dimension is not significant.

Based on the foregoing, we reject the first major nutritional hypothesis and accept the alternative hypothesis that "There is a statistically significant effect at the level of significance $(\alpha \leq 0.05)$ for social media elements (conversations, groups, participation, partnership, relationships) in promoting small projects commodities in Kuwait".

Ho1-1 "There is no statistically significant effect at the level of significance $(\alpha \leq 0.05)$ of the talks in promoting small projects commodities in the State of Kuwait".

\begin{tabular}{|c|c|c|c|c|c|c|c|c|c|c|}
\hline \multirow{2}{*}{ Ind } & \multicolumn{2}{|c|}{$\begin{array}{c}\text { Model } \\
\text { Summery } \\
\end{array}$} & \multicolumn{3}{|c|}{ ANOVA } & \multicolumn{5}{|c|}{ Coeffecient } \\
\hline & $\mathbf{R}$ & $\mathbf{r}^{2}$ & $\mathbf{F}$ & Df & $\begin{array}{l}\text { Sig } \\
\text { F }\end{array}$ & Dep & B & S.R & $\mathbf{T}$ & $\begin{array}{l}\text { Sig } \\
\text { t* }^{*}\end{array}$ \\
\hline $\begin{array}{l}\text { promoting commodities of } \\
\text { small projects }\end{array}$ & .524 & .274 & 23.786 & 1 & .000 & conversations & .497 & .102 & 4.877 & .000 \\
\hline
\end{tabular}

The results of Table (3) indicate that the value of $(\mathrm{r}=.524)$, and this means that there is a positive relationship between the dimension (talks) and (promotion of commodities for small projects). It turns out that the value of the coefficient of determination $(\mathrm{r} 2=.274)$, this means that after (the talks), he explained $(27.4 \%)$ of the variance in (promoting small commodities projects), while the other factors remain constant. It also shows that the value of (F) has reached (23.786) at a confidence level $(\mathrm{Sig}=0,000)$, and this confirms the significance of the slope at $(\alpha$ $\leq 0.05)$ and at one degree.

It also appears from the table of coefficients that the value of $(B=.497)$ and that the value of $(t=4.877)$ is at a confidence level $(\mathrm{Sig}=0.000)$ and this confirms the significance of the coefficient at the level $(\mathrm{a} \leq 0.05)$. Based on the above, we reject the first nihilistic sub-hypothesis and accept the alternative sub-hypothesis which states that:

"There is no statistically significant effect at the level of significance $(\mathrm{a} \leq 0.05)$ of the talks in promoting small enterprise commodities in the State of Kuwait."

Ho1-2: "There is no statistically significant effect at the level of significance $(\mathrm{a} \leq 0.05)$ to participate in promoting small enterprise commodities in the State of Kuwait".

\begin{tabular}{|c|c|c|c|c|c|c|c|c|c|c|}
\hline \multirow{2}{*}{ Ind } & \multicolumn{2}{|c|}{$\begin{array}{c}\text { Model } \\
\text { Summery }\end{array}$} & \multicolumn{3}{|c|}{ ANOVA } & \multicolumn{5}{|c|}{ Coeffecient } \\
\hline & $\mathbf{R}$ & $\mathbf{r}^{2}$ & $\mathbf{F}$ & Df & $\begin{array}{l}\text { Sig } \\
\text { F }\end{array}$ & Dep & B & S.R & $\mathbf{T}$ & $\begin{array}{c}\text { Sig } \\
t^{*}\end{array}$ \\
\hline $\begin{array}{l}\text { promoting commodities of } \\
\text { small projects }\end{array}$ & .604 & .365 & 36.182 & 1 & .000 & PARTICIPATE & .572 & .095 & 6.015 & .000 \\
\hline
\end{tabular}

The results of Table (4) indicate that the value of $(r=.604)$, and this means that there is a positive relationship between the (participation) dimension and (promotion of commodities for small projects). 
It turns out that the value of the coefficient of determination $(\mathrm{r} 2=.365)$, and this means that after (participation) has explained about (37\%) of the variance in (promoting of commodities for small projects), with other factors remaining constant.

It also turns out that the value of $(\mathrm{F})$ has reached (36.182) at a confidence level ( $\mathrm{Sig}=0,000)$, and this confirms the significance of the slope at the level of $(\mathrm{a} \leq 0.05)$ and at one degree. It also appears from the table of transactions that the value of $(\mathrm{B}=.572)$ and that the value of $(\mathrm{t}=6.015)$ is at a confidence level $(\mathrm{Sig}=0.000)$ and this confirms the significance of the coefficient at the level of (a (0.05). Based on the foregoing, we reject the second nihilistic hypothesis and accept the alternative sub-hypothesis which states that: "There is a statistically significant effect at the level of significance $(a \leq 0.05)$ to participate in promoting of commodities for small projects in the State of Kuwait"

Ho1-3: "There is no statistically significant effect at the level of significance $(a \leq 0.05)$ for groups in promoting small enterprise commodities in the State of Kuwait".

\begin{tabular}{|c|c|c|c|c|c|c|c|c|c|c|}
\hline \multirow{2}{*}{ Ind } & \multicolumn{2}{|c|}{$\begin{array}{c}\text { Model } \\
\text { Summery } \\
\end{array}$} & \multicolumn{3}{|c|}{ ANOVA } & \multicolumn{5}{|c|}{ Coeffecient } \\
\hline & $\mathbf{R}$ & $\mathbf{r}^{2}$ & $\mathbf{F}$ & Df & Sig F & Dep & B & S.R & $\mathbf{T}$ & $\underset{t^{*}}{\text { Sig }}$ \\
\hline $\begin{array}{l}\text { promoting commodities of } \\
\text { small projects }\end{array}$ & .495 & .245 & 20.396 & 1 & 0.000 & Groups & .409 & .090 & 4.516 & 0.000 \\
\hline
\end{tabular}

The results of Table (5) indicate that the value of $(\mathrm{r}=.495)$, which means that there is a positive relationship between the (groups) dimension and (the promotion of small projects commodities). It turns out that the value of the coefficient of determination $(\mathrm{r} 2=.245)$, and this means that after (groups) has explained about $(25 \%)$ of the variance in (promoting small business commodities), with the other factors remaining constant. It also turns out that the value of $(\mathrm{F})$ has reached (20.396) at a confidence level ( $\mathrm{Sig}=0,000)$, and this confirms the significance of the slope at the level of $(\mathrm{a} \leq 0.05)$ and at one degree.

Also, it appears from the coefficients table that the value of $(\mathrm{B}=.409)$ and that the value of $(\mathrm{t}=4.516)$ is at a confidence level $(\mathrm{Sig}=0.000)$ and this confirms the significance of the coefficient at the level $(\mathrm{a} \leq 0.05)$. Based on the foregoing, we reject the third nihilistic hypothesis and accept the alternative sub-hypothesis that: "There is a statistically significant effect at the level of significance $(a \leq 0.05)$ for groups in promoting small enterprise commodities in the State of Kuwait".

Ho1-4: "There is no statistically significant effect at the level of significance $(a \leq 0.05)$ for relationships in promoting small enterprise commodities in the State of Kuwait"

\begin{tabular}{|c|c|c|c|c|c|c|c|c|c|c|}
\hline \multirow{2}{*}{ Ind } & \multicolumn{2}{|c|}{$\begin{array}{c}\text { Model } \\
\text { Summery }\end{array}$} & \multicolumn{3}{|c|}{ ANOVA } & \multicolumn{5}{|c|}{ Coeffecient } \\
\hline & $\mathbf{r}$ & $\mathbf{r}^{2}$ & $\mathbf{F}$ & Df & Sig F & Dep & B & S.R & $\mathbf{T}$ & $\begin{array}{c}\text { Sig } \\
\mathbf{t}^{*}\end{array}$ \\
\hline $\begin{array}{l}\text { promoting commodities of } \\
\text { small projects }\end{array}$ & .413 & .171 & 12.969 & 1 & 0.000 & relations & .302 & .084 & 3.601 & 0.000 \\
\hline
\end{tabular}

The results of Table (5) indicate that the value of $(\mathrm{r}=.413)$, and this means that there is a positive relationship between the (Relationships) dimension and (Small Business Goods Promotion). It turns out that the value of the coefficient of determination $(\mathrm{r} 2=.171)$, which means that after (relationships) has explained $(17.1 \%)$ of the variance in (promoting small commodities projects), with the other factors remaining constant. It also turns out that the value of $(\mathrm{F})$ has reached (12.969) at a confidence level ( $\mathrm{Sig}=0,000)$ and this confirms the significance of the slope at the level of $(\mathrm{a} \leq 0.05)$ and at one degree.

The table of transactions also shows that the value of $(\mathrm{B}=.302)$ and that the value of $(\mathrm{t}=3.601)$ is at a confidence level $(\mathrm{Sig}=0,000)$ and this confirms the coefficient of the factor at the level of $(\mathrm{a} \leq 0.05)$.

Based on the foregoing, we reject the fourth nihilistic hypothesis, and accept the alternative sub-hypothesis, which states that: "There is a statistically significant effect at the level of significance $(a \leq 0.05)$ for relationships in promoting small enterprise commodities in the State of Kuwait".

11. Results: "There is a statistically significant effect at the level of significance $(a \leq 0.05)$ of the elements of social media (conversations, groups, participation, partnership, relations) in promoting the commodities of small projects in the State of Kuwait.

12. Recommendations: Through the theoretical framework and through informing the researcher of many previous studies that are concerned with the subject of social media and promoting the commodities of small projects in the State of Kuwait, the researcher recommends the following: 
1. The need for those in charge of focusing on social media; Facebook, Instagram, Twitter and LinkedIn as a means of communication with customers to promote the goods of small projects in the State of Kuwait because of their characteristics and features.

2. Focus on giving social media more care and attention to the mechanism of adopting credible and reliable information to reach those wishing to establish small projects in the State of Kuwait, helping them to adopt it.

3. The need for those in charge of social media to encourage influential entrepreneurs to share their own experiences and expertise to promote new entrepreneurs.

4. The need for those in charge of social media to communicate with the owners of projects via social media and motivate them to give positive evaluations for the promotion.

\section{References}

Arabic references:

Bishmaf, Muhammad (2016). "The impact of social media marketing on the intention to purchase: Understanding the Mark as a Modified Variable", Unpublished Master Thesis, Applied Sciences University, Amman, Jordan.

Hamdan, Alia (2016). "The impact of social media on the electronic purchasing decision process in the fashion sector", unpublished Master Thesis, Applied Sciences University, Amman, Jordan.

Al-Dabsi, Abdul Karim, and Chefs, Zuhair (2013). "The role of social media in shaping public opinion among Jordanian university students," Journal of Humanities and Social Sciences Studies, 40 (1), 66-81.

El-Sayed, Amina, and Abdel-Al, Heba (2009), "Social Networks and their Impact on the Specialist and Library: A Comprehensive Study of Presence and Use of Facebook", The Thirteenth Conference of Libraries and Information Professionals, Cairo, Egypt.

Al-Shibli, Obedient (2014). "Factors affecting adoption and purchase intent using social media as a marketing tool", unpublished $\mathrm{PhD}$ thesis, University of Islamic Sciences, Amman, Jordan.

Obaidat, Muhammad and Al-Ghadeer, Hamad (2011). "The effect of the elements of the marketing mix on Jordanian pharmacists' preference for the local drug compared to its foreign counterpart", Administrative Sciences Studies, 38 (1), 180-198.

Idan, Ehsan (2015), The Use of Social Media in Performing Customer Relationship Management, Unpublished Master Thesis, Middle East University, Amman, Jordan.

Qubu', Sinan Ahmed, (2016), The Impact of Using Social Media Networks on Knowledge of Customers, Acquisition and Retention of Customers, Marka VIP Company Study, Unpublished Master Thesis (University of the Middle East, Amman, Jordan.

Al-Najjar, Fayez, Al-Najjar, Nabil and Al-Zoubi, Majed (2013), "Scientific Research Methods: An Applied Perspective", Dar Al-Hamid for Publishing and Distribution, Amman, Jordan.

Al-Nsour, Hala, Al-Manasrah, Aksmari, and Ziadat, Muhammad (2016). "The Impact of Marketing Using Social Media on the Intention to Buy in Jordan," Jordanian Journal of Business Administration, 12 (3), $519-530$

\section{English References}

Akpan, S. (2016). "The Influence of Cultural Factors on Consumer Buying Behaviour

(A Case Study of PORK". British Journal of Marketing Studies, 4(6), 44-57.

Barber N. and J.M.Scarcelli (2009)."Clean restrooms: how important are they to restaurant Consumers?", Journal of Food Service, 20(6), 309-320.

Cheng, C., Lin, S., \& Tsai, C. (2014). "Investigating Consumer Preferences in Choosing Vegetarian Restaurants Using Conjoint Analysis”, Current Urban Studies, 2(3), 279.

Coursaris, C., \& Van Osch, W. (2016). "Exploring the Effects of Source Credibility

on Information Adoption on YouTube", International Conference on HCI in Business, Government and Organizations, Springer International Publishing, USA, 16-25.

Dou, X., Walden, J., Lee, S., \& Lee, J. (2012). "Does source matter? Examining source effects in online product reviews", Computers in Human Behavior, 28(5), 15551563.

Ehsan, U. (2012). "Factors important for the selection of fast food restaurants: an empirical study across three cities of Pakistan", British Food Journal, 114(9), 1251-1264.

Fulcher, C. (2014). "Community commons: A unifying public good website for healthy, sustainable, and livable communities", National Civic Review, 103(1), 912.

Goyal, M. (2016). "A study of impact of social media on consumer behavior in restaurant industry of Jaipur city", International Journal of Advance Research and Innovative Ideas in Education, 2(3), 2435-2441.

Hu, X. (2015). “Assessing Source Credibility On Social Media-An Electronic WordOf-Mouth Communication Perspective”, Unpublished PHD Dissertation, Bowling Green State University, USA.

Kabadayi, S., \& Price, K. (2014). "Consumer-brand engagement on Facebook: liking 
and commenting behaviors", Journal of Research in Interactive Marketing, 8(3), 203-223.

Lafferty, B., \& Goldsmith, R. (1999). "Corporate credibility's role in consumers' attitudes and purchase intentions when a high versus a low credibility endorser is used in the ad", Journal of business research, 44(2), 109116.

Liu, Y., \& Lopez, R. A. (2016). "The impact of social media conversations on consumer brand choices", Marketing Letters, 27(1), 1-13.

Mohan Raj. P. \& Ananth, S. (2016). "Brand Preferences of Newspapers- Factor Analysis Approach", Research Journal of Economics and Business Studies, 5(11), 17-26.

Parveen, F., Jaafar, N., \& Sulaiman, A. (2015). "Role of Social Media on Information

Accessibility", PACIS, 8(4), 237- 253.

Song, S., \& Yoo, M. (2016). “The role of social media during the pre-purchasing stage", Journal of Hospitality and Tourism Technology, 7(1), 84-99.

Tang, L., \& Liu, H. (2010). “Understanding group structures and properties in social media In Link Mining: Models, Algorithms, and Applications”, Springer New

York, USA. , 51 (4) 83-491. 